\title{
Effects of Slag Content and Composition on the Reducibility of Iron Oxide Including $\mathrm{CaO}_{-} \mathrm{SiO}_{2}-\mathrm{Fe}_{t} \mathrm{O}$ Slag
}

\author{
Hideki ONO-NAKAZATO, Kouji OKADA ${ }^{1)}$ and Tateo USUI \\ Department of Materials Science and Processing, Graduate School of Engineering, Osaka University, 2-1 Yamadaoka, Suita, \\ Osaka 565-0871 Japan. $\quad$ 1) Formerly at Graduate School of Osaka University. Now at JFE Steel Corporation, Japan.
}

(Received on September 1, 2004; accepted on December 3, 2004)

\begin{abstract}
In the sintering with lower slag ratio, the melt quantity decreases, and the agglomeration do not progress sufficiently. It is necessary to secure the melt quantity by silicate melt mainly composed of $\mathrm{Fe}_{x} \mathrm{O}-\mathrm{SiO}_{2}$ system and to control ideally the composition and the generation place of the melt. In the present study, iron ore sinter is simulated by an iron oxide pellet added with ( $\mathrm{CaO}-) \mathrm{SiO}_{2}-\mathrm{Fe}_{t} \mathrm{O}$ slag particles, and the effects of the slag content, the composition, the holding time at $1573 \mathrm{~K}$ and the slag particle size on the hydrogen reduction behavior of the iron oxide pellet including $(\mathrm{CaO}-) \mathrm{SiO}_{2}-\mathrm{Fe}_{t} \mathrm{O}$ slag particles have been investigated at $1173 \mathrm{~K}$. In the initial stage of reduction, the fractional reduction is higher when the slag content is higher. With proceeding the reduction, the fractional reduction of the sample with the higher slag content becomes lower than the sample with the lower slag content. The reduction rate decreases with the increase of the slag content. The ratio of the pore area with over $100 \mu \mathrm{m}$ pore size increases with the increase of slag content. On the other hand, the final fractional reduction decreases with the increase of the slag content. From this fact, it is considered that the increase of macro pore over $100 \mu \mathrm{m}$ does not affect on the improvement of reducibility, and the microporosity under $100 \mu \mathrm{m}$ may become an influential factor. On the slag composition, the final fractional reduction of the pellet including $\mathrm{Fe}_{t} \mathrm{O}-\mathrm{SiO}_{2}$ slag is better. This is because that the silicate slag is difficult to permeate nor block up the pore.
\end{abstract}

KEY WORDS: ironmaking; reducibility; iron oxide; pore; permeation; iron ore sinter.

\section{Introduction}

From the recent raw material circumstances of iron and steel industries in Japan, the use of iron ores with high crystal water from Australia increases year by year. There is a trend to increase an import amount of Marra Mamba ore with higher powdered ore rate, instead of pisolite ore with higher $\mathrm{Al}_{2} \mathrm{O}_{3}$ and $\mathrm{SiO}_{2}$ contents, in particular. When the use of the limonite increases, the ratio of iron ore sinter increases, since the yield of the lump ore is worse and the strength is not attained enough. ${ }^{1,2)}$ As a result, iron ore sinter with lower slag ratio is required in order to avoid the increase of slag ratio in the blast furnace. If the slag ratio of iron ore sinter can be lowered, the following merits can be expected: (1) Improvement of the reducibility and the stabilization of the blast furnace operation, (2) The reduction in the slag treatment cost and (3) The reduction in the auxiliary feedstock cost. ${ }^{1)}$ Accordingly, the establishment of the lower slag sintering process by using Marra Mamba ore, of which the amount of gangue minerals is less than the pisolite ore, has been desired. Generally speaking, in the sintering with lower slag ratio, the melt quantity decreases, and the agglomeration do not progress sufficiently. It is necessary to secure the melt quantity by silicate melt mainly composed of $\mathrm{Fe}_{x} \mathrm{O}-\mathrm{SiO}_{2}$ system and to control ideally the composition and the generation place of the melt. ${ }^{3)}$ It is said that the use of $\mathrm{Fe}_{x} \mathrm{O}$ component (higher $\mathrm{Fe}_{x} \mathrm{O}$ ) makes the reducibility drastically lower for the decrease in the microporosity, although it is effective in maintaining the yield and the strength of iron ore sinter. ${ }^{4)}$ On the other hand, when the use of iron ores with high crystal water is increased, the improvement in the reducibility can be expected from the increase in the microporosity.

In the present study, iron ore sinter is simulated by an iron oxide pellet added with $(\mathrm{CaO}-) \mathrm{SiO}_{2}-\mathrm{Fe}_{t} \mathrm{O}$ slag particles, and the experiment on the reducibility is carried out. Namely, the effects of the slag content and composition on the reducibility of iron oxide including $(\mathrm{CaO}-) \mathrm{SiO}_{2}-\mathrm{Fe}_{t} \mathrm{O}$ slag have been investigated.

\section{Experimental}

From the distributions of temperature and chemical composition in sinter layer ${ }^{5)}$ and the $\mathrm{Fe}-\mathrm{O}$ phase diagram, ${ }^{6}{ }^{6}$ the experimental conditions were determined as follows: $P_{\mathrm{O}_{2}}$ (oxygen partial pressure) $=1.8 \times 10^{-6} \mathrm{~atm}$ and H.T. (holding temperature of molten slag at high temperature) $=1573 \mathrm{~K}$. The compositions of slag included in the iron oxide pellet are shown in Table 1. The compositions in Table 1 are also plotted in Fig. 1, which shows the reducibility of $\mathrm{CaO}-$ $\mathrm{SiO}_{2}-\mathrm{Fe}_{t} \mathrm{O}$ slag ${ }^{7)}$ summarized on the isothermal section of $\mathrm{CaO}-\mathrm{SiO}_{2}-\mathrm{Fe}_{t} \mathrm{O}$ diagram ${ }^{8)}$ at $1573 \mathrm{~K}$ and $P_{\mathrm{O}_{2}}=1.8 \times 10^{-6}$ atm. The slag compositions are on the liquidus at $1573 \mathrm{~K}$. The slag samples were made as follows: The reagent grade 
Table 1. The chemical compositions of $(\mathrm{CaO}-) \mathrm{SiO}_{2}-\mathrm{Fe}_{t} \mathrm{O}$ slag included in the $\mathrm{Fe}_{2} \mathrm{O}_{3}$ pellet.

\begin{tabular}{c|c|r|c}
\multicolumn{5}{|c}{} & \multicolumn{1}{c}{} & \multicolumn{2}{c}{$\left.\mathrm{FiO}_{2} \%\right)$} \\
\hline Slag & $\mathrm{CaO}$ & $\mathrm{SiO}_{2}$ & $\mathrm{O}$ \\
\hline $\mathrm{A}$ & 20.5 & 18.3 & 61.2 \\
$\mathrm{~B}$ & 11.2 & 6.1 & 82.7 \\
$\mathrm{C}$ & - & 23.4 & 76.6 \\
\hline
\end{tabular}

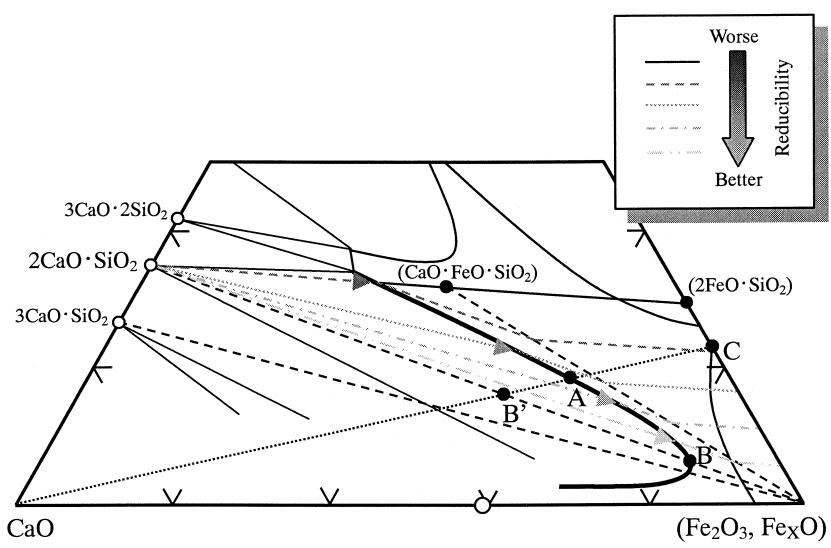

Fig. 1. The reducibility of $\mathrm{CaO}-\mathrm{SiO}_{2}-\mathrm{Fe}_{t} \mathrm{O}$ slag summarized on the isothermal section of the phase diagram at $1573 \mathrm{~K}$ and $P_{\mathrm{O}_{2}}=1.8 \times 10^{-6} \mathrm{~atm}$.
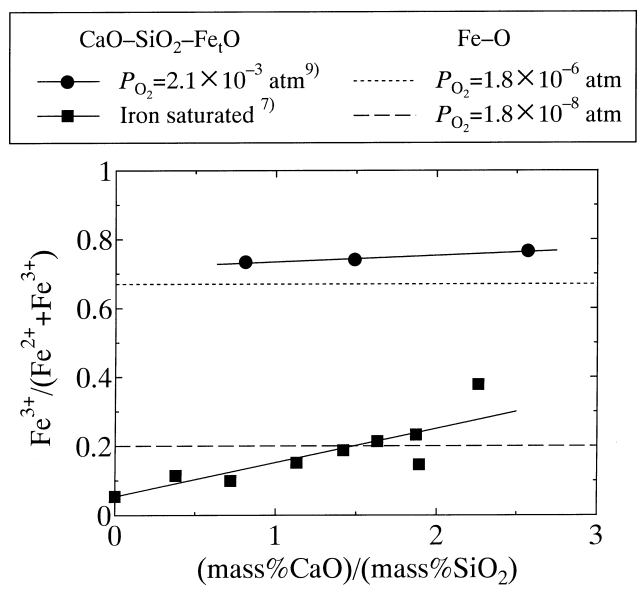

Fig. 2. Relation between $\mathrm{Fe}^{3+} /\left(\mathrm{Fe}^{2+}+\mathrm{Fe}^{3+}\right)$ and (mass\%CaO)/ $\left(\operatorname{mass} \% \mathrm{SiO}_{2}\right.$ ) at $1573 \mathrm{~K}$.

of $\mathrm{Fe}_{2} \mathrm{O}_{3}, \mathrm{SiO}_{2}$ and $\mathrm{CaO}$ and the preliminary made $\mathrm{Fe}_{x} \mathrm{O}$ were mixed at the mass ratio shown in Table 1 and were pelletized by adding ethanol. The relationship of $\mathrm{Fe}^{3+} /\left(\mathrm{Fe}^{2+}+\mathrm{Fe}^{3+}\right)$ in $\mathrm{CaO}-\mathrm{SiO}_{2}-\mathrm{Fe}_{t} \mathrm{O}$ system under $P_{\mathrm{O}_{2}}=$ $2.1 \times 10^{-3} \mathrm{~atm}^{9)}$ or iron saturated condition ${ }^{7)}$ at $1573 \mathrm{~K}$ and $(\mathrm{mass} \% \mathrm{CaO}) /\left(\operatorname{mass} \% \mathrm{SiO}_{2}\right)$ is shown in Fig. 2. From Fig. 2, it is found that the value for $\mathrm{Fe}^{3+} /\left(\mathrm{Fe}^{2+}+\mathrm{Fe}^{3+}\right)$ increases with increasing $(\operatorname{mass} \% \mathrm{CaO}) /\left(\operatorname{mass} \% \mathrm{SiO}_{2}\right)$. However, in the present study, the $\mathrm{Fe}^{3+} /\left(\mathrm{Fe}^{2+}+\mathrm{Fe}^{3+}\right)$ value in $\mathrm{Fe}-\mathrm{O}$ system under $P_{\mathrm{O}_{2}}=1.8 \times 10^{-6}$ atm at $1573 \mathrm{~K}, 0.67,{ }^{6)}$ was adopted to be a reference. That is to say, the mixing ratio of $\mathrm{Fe}_{2} \mathrm{O}_{3}$ and $\mathrm{Fe}_{x} \mathrm{O}$ was fixed to be $\mathrm{Fe}_{2} \mathrm{O}_{3}: \mathrm{Fe}_{x} \mathrm{O}=65: 35$ in mixing the slag sample. After the pelletized sample was dried at $433 \mathrm{~K}$ for a day, it was put in an alumina crucible and was heated at $1273 \mathrm{~K}$ in Ar for $3 \mathrm{~h}$. Then, the sample was crushed, powdered and divided by the particle size of 0.3 to $1.0 \mathrm{~mm}$ or 1.0 to $1.7 \mathrm{~mm}$. The slag particle was

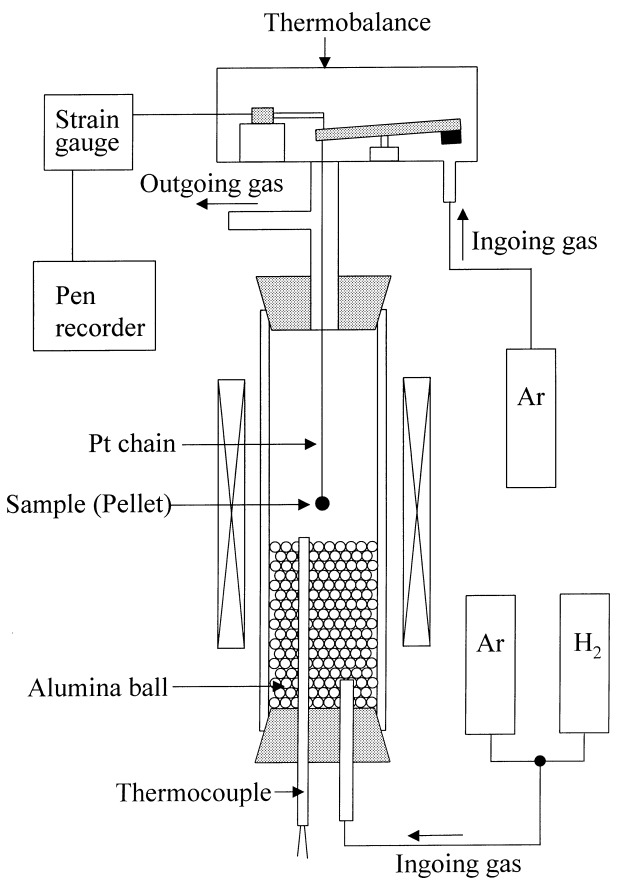

Fig. 3. Schematic cross section of experimental apparatus.

mixed in $\mathrm{Fe}_{2} \mathrm{O}_{3}$ at the ratio of $0,1,3$ or 5 mass $\%$, and the sample was pelletized. This pelletized sample was dried at $433 \mathrm{~K}$ for a day and was used as an experimental sample, of which the weight is about $4 \mathrm{~g}$. The arrangement of the experimental apparatus is shown in Fig. 3. The experiments were conducted using an electric furnace with a thermobalance. After the sample weight was measured by an electric balance, it was hung in a platinum chain. Then, it was heated in $\mathrm{Ar}$ and was held for 10 or $60 \mathrm{~min}$ at $1573 \mathrm{~K}$ for melting of the included slag. Subsequently, the temperature was decreased to $1173 \mathrm{~K}$, and Ar was switched to $\mathrm{H}_{2}$. The reduction experiments were started with $\mathrm{H}_{2}$ at a flow rate of $1.67 \times 10^{-5} \mathrm{~m}^{3} / \mathrm{s}$ (s.t.p.). The weight change of the sample by the reduction was recorded. After the reduction was finished, the sample was cooled in an Ar stream. After the experiment, the surface and the cross section of the sample were observed by a laser microscope.

\section{Results and Discussion}

\subsection{The Surface and Cross-sectional Observation of the Sample}

The surfaces of the samples including Slag B after reduction are shown in Fig. 4. The cracks are found in the samples, and the amount of crack tends to increase with increasing the slag content, the holding time at $1573 \mathrm{~K}$ and the slag particle size. Approximately, similar cracks were found in the samples including Slag A or C. On the slag particle size, the larger cracks are found when $d_{\mathrm{s}}$ (diameter of slag) $=1.0$ to $1.7 \mathrm{~mm}$ in comparison to $d_{\mathrm{s}}=0.3$ to $1.0 \mathrm{~mm}$. The cause is considered that the macro pores with larger pore size form by the penetration of molten slag when the diameter of slag is larger. From these facts, it is considered that the stress in the circumference of the slag particle occured by the contraction of sample in the cooling $^{10,11)}$ and the formation of macro pore by the penetration of molten slag become the very influential factors on 
the generation of crack. The cross-sectional view of the sample including 5 mass $\%$ of Slag A, B or C after reduction by a laser microscope is shown in Fig. 5 under the conditions of $d_{\mathrm{s}}=0.3$ to $1.0 \mathrm{~mm}$ and $t_{1573}$ (holding time at $1573 \mathrm{~K})=60 \mathrm{~min}$. The white parts, the black parts, and the gray parts in the pictures show the reduced iron, the pore and the slag, respectively. In Slag A and B, it is observed that the molten slag permeates the pore in the circumference, but the slag does not block up the whole of the pore. Moreover, it is found that the place where the slag originally exists becomes newly a macroscopic pore after the penetration of the molten slag. On the other hand, in slag $C$, it is observed that the molten slag little permeates the pore in the circumference.

\subsection{The Reducibility of Oxide Pellet Including CaO- $\mathrm{SiO}_{2}-\mathrm{Fe}_{t} \mathrm{O}$ Slag Particles}

The reduction behavior of the oxide pellet samples including Slag A, B or C is shown in Figs. 6 to 8, respectively, under the conditions of $d_{\mathrm{s}}=0.3$ to $1.0 \mathrm{~mm}$ and $t_{1573}=10$ or $60 \mathrm{~min}$. Through Figs. 6 to 8 , it is found that the reducibility tends to become worse as the slag content increases or the holding time at $1573 \mathrm{~K}$ is longer. It is considered the deterioration of the reducibility is caused by the penetration of the molten slag in the pore. When the pore is

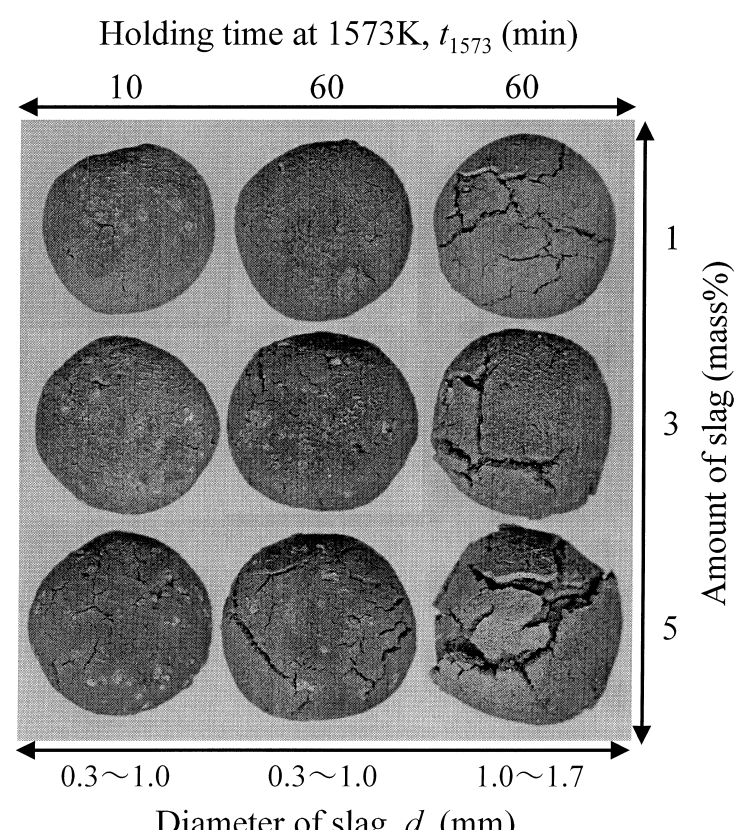

Fig. 4. Shape of the pellets including slag B after reduction. blocked, the diffusion of gas is prevented, and the specific surface area for the reduction reaction decreases. Accordingly, the reducibility deteriorates when the slag content is more increased or the holding time is longer because the molten slag can sufficiently permeate the pore. In Fig. 9, the influence of slag content on the fractional reductions at 5 and $20 \mathrm{~min}$ is shown under the conditions of $d_{\mathrm{s}}=0.3$ to $1.0 \mathrm{~mm}$ and $t_{1573}=60 \mathrm{~min}$. In the initial stage of reduction, the fractional reduction is found to be better when the slag content is higher. This is because many cracks are found in the sample when the slag content is higher. That is to say, the cracks were found in the samples after reduction in Sec. 3.1. It is considered that these cracks already occur in the stage which cools from $1573 \mathrm{~K}$ (slag penetration temperature) to $1173 \mathrm{~K}$ (reduction temperature). With proceeding the reduction, the fractional reduction of the sample with the higher slag content becomes lower than the sample with the lower slag content. The relationship between the slag content and the final fractional reduction is shown in Fig. 10. The final fractional reduction is defined to be that when the change of the fractional reduction is not found over $3 \mathrm{~min}$ in the present study. The final fractional reduction decreases with the increase of slag content and with the decrease of the slag particle size. This is because the diffusion of the reducing gas is prevented and the specific surface area for the reduction reaction decreases by the molten slag, which permeates and blocks up the pore. As the result, with the increase of slag content, the final fractional reduction decreases in spite of the existence of large number of cracks. The relationship between the ratio of the pore area and the slag content on the pore-size distribution is shown in Fig. 11 for the sample including Slag B under the conditions of $d_{\mathrm{s}}=0.3$ to $1.0 \mathrm{~mm}$ and $t_{1573}=60 \mathrm{~min}$. The ratio of pore area and the pore-size were investigated by image processing from the cross-sectional observation of the sample. Approximately, a similar relationship was found in the sample including Slag A or C. The ratio of the pore area with over $100 \mu \mathrm{m}$ pore size increases with the increase of slag content. On the other hand, the final fractional reduction decreases with the increase of the slag content. From this fact, it is considered that the increase of macro pore over $100 \mu \mathrm{m}$ does not affect on the improvement of reducibility, and the microporosity under $100 \mu \mathrm{m}$ may become an influential factor. On the slag composition, the final fractional reduction of the pellet including Slag C is better. This is because that Slag $C$ is rather difficult to permeate in comparison to Slag A and B from the viewpoint of viscosity, ${ }^{12)}$ although the reducibility of Slag $\mathrm{C}$ itself is worse than that of slag A

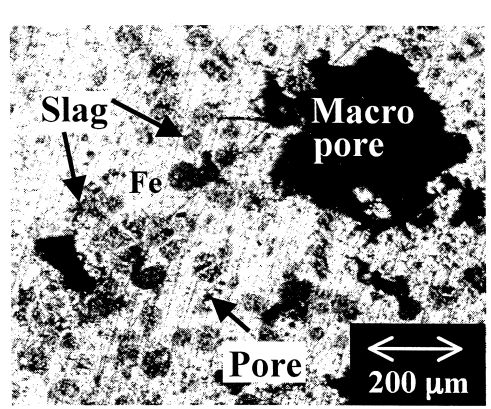

(a) Slag A

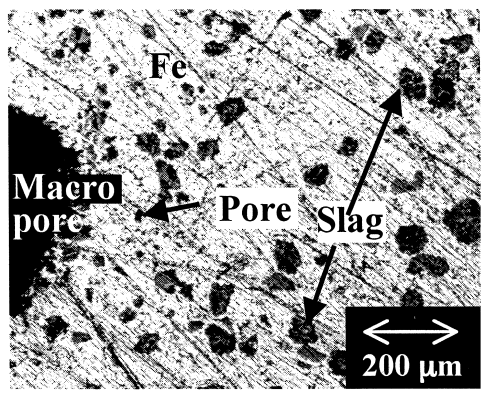

(b) Slag B

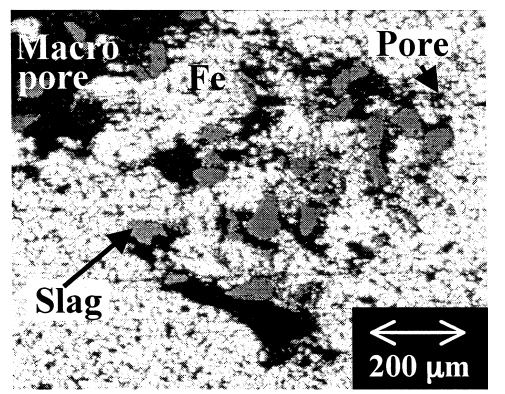

(c) Slag C

Fig. 5. Cross-sectional view of the pellet after reduction under the conditions of $d_{\mathrm{s}}=0.3$ to $1.0 \mathrm{~mm}$ and $t_{1573}=60 \mathrm{~min}$. 


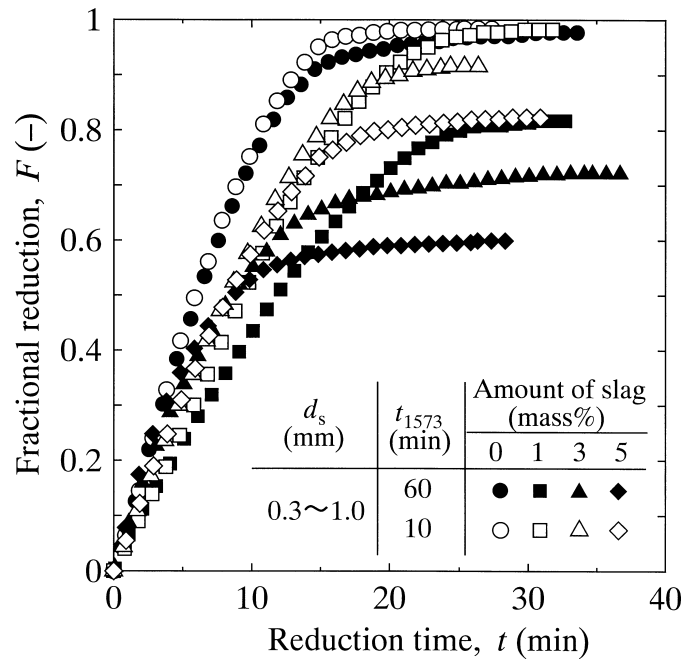

Fig. 6. Hydrogen reduction behavior of the pellet including Slag A at $1173 \mathrm{~K}$.

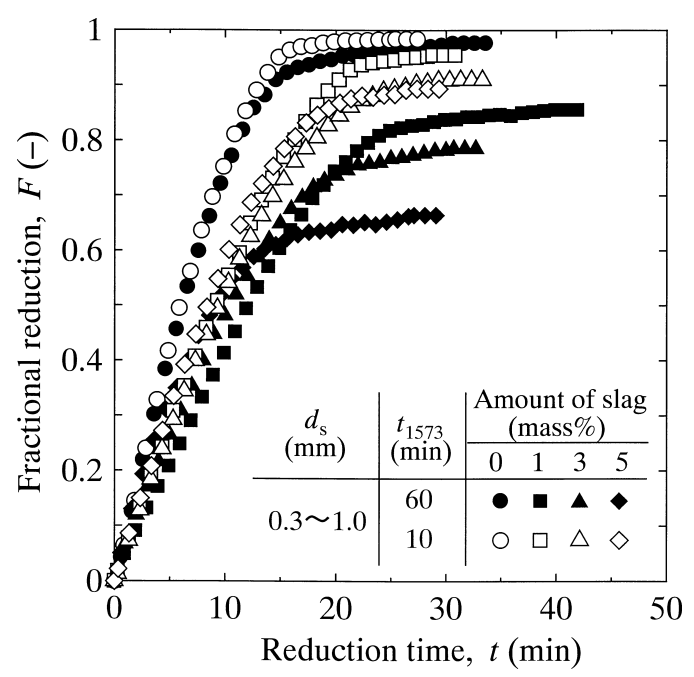

Fig. 7. Hydrogen reduction behavior of the pellet including Slag $\mathrm{B}$ at $1173 \mathrm{~K}$.

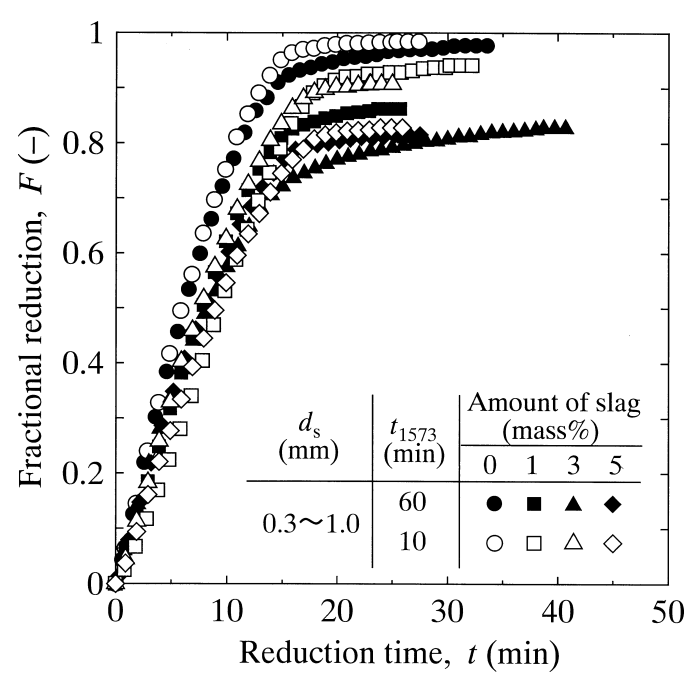

Fig. 8. Hydrogen reduction behavior of the pellet including Slag $\mathrm{C}$ at $1173 \mathrm{~K}$.

or $\mathrm{B}^{7,13,14)}$ On the other hand, both slag A and B easily permeate the pore, and the reducibility becomes worse. When the reducibility of the pellet including Slag A and B is com-

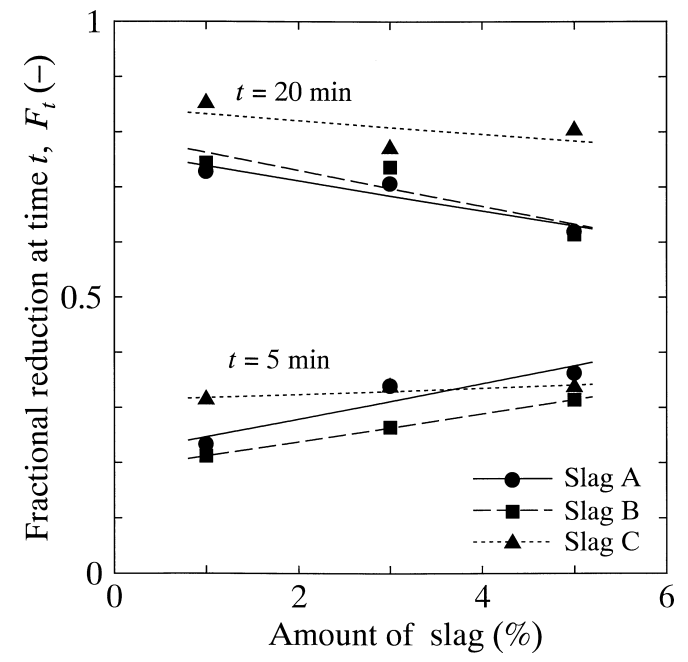

Fig. 9. Influence of the amount of slag on the fractional reduction at 5 or $20 \mathrm{~min}$ under the conditions of $d_{\mathrm{s}}=0.3$ to $1.0 \mathrm{~mm}$ and $t_{1573}=60 \mathrm{~min}$.
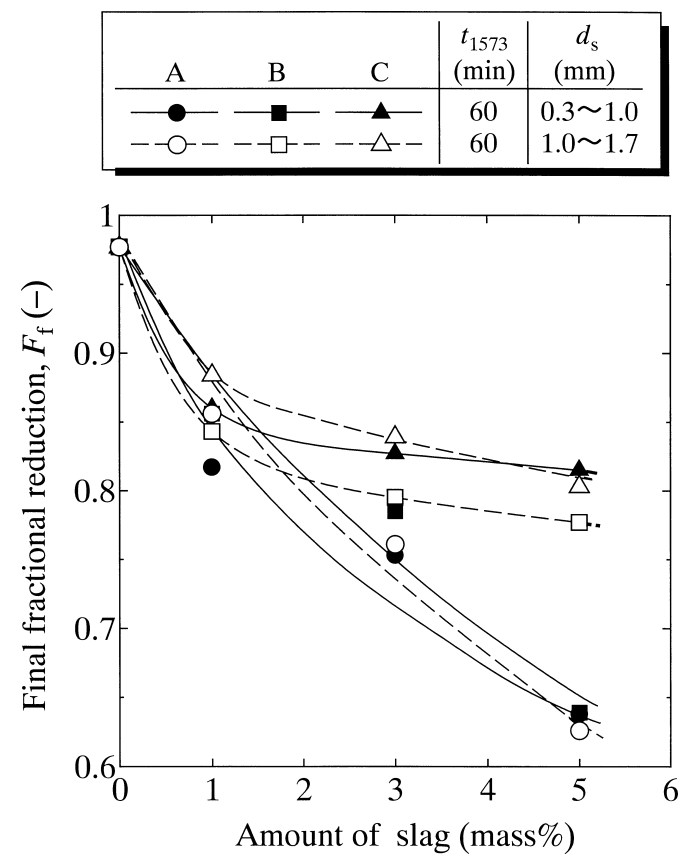

Fig. 10. Relation between $F_{\mathrm{f}}$ and the amount of slag.

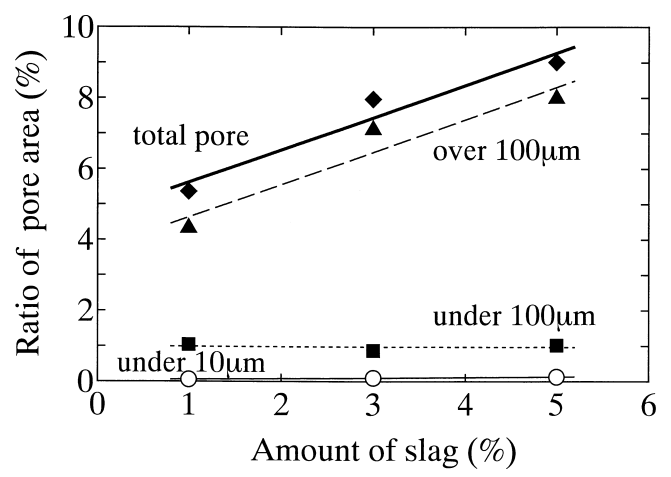

Fig. 11. Relation between the ratio of pore area and the amount of slag for the sample including Slag B under the conditions of $d_{\mathrm{s}}=0.3$ to $1.0 \mathrm{~mm}$ and $t_{1573}=60 \mathrm{~min}$.

pared, the reducibility of the pellet including Slag B is a little better than that including Slag A, which is in accordance with the reducibility of slag A and B themselves. ${ }^{7,13,14)}$ 


\section{Conclusions}

The effects of the slag content, the composition, the holding time at $1573 \mathrm{~K}$ and the slag particle size on the hydrogen reduction behavior of the iron oxide pellet including $(\mathrm{CaO}-) \mathrm{SiO}_{2}-\mathrm{Fe}_{t} \mathrm{O}$ slag particles have been investigated at $1173 \mathrm{~K}$. The following conclusions are obtained:

(1) In the initial stage of reduction, the fractional reduction is better as the slag content is higher. This is because many cracks exist in the sample when the slag content is higher. With proceeding the reduction, the fractional reduction of the sample with the higher slag content becomes lower than the sample with the lower slag content. The reduction rate decreases with the increase of the slag content.

(2) The ratio of the pore area with over $100 \mu \mathrm{m}$ pore size increases with the increase of slag content. On the other hand, the final fractional reduction decreases with the increase of the slag content. From this fact, it is considered that the increase of macro pore over $100 \mu \mathrm{m}$ does not affect on the improvement of reducibility, and the microporosity under $100 \mu \mathrm{m}$ may become an influential factor.

(3) On the slag composition, the final fractional reduction of the pellet including $\mathrm{Fe}_{t} \mathrm{O}-\mathrm{SiO}_{2}$ slag is better. This is because the silicate slag is difficult to permeate nor block up the pore.

\section{REFERENCES}

1) Y. Hosotani: Private Communication.

2) T. Kawaguchi: Private Communication.

3) E. Kasai: Commencement of Creating Porous Meso-mosaic Texture Sinter, ed. by Examination Committee on Agglomeration of Iron Ores Unsuitable for Sintering, ISIJ, Tokyo, (2001), 39.

4) T. Inazumi: Iron Ore Sinter-Review of Steps Taken to Overcome the Challenges Posed Japan's Lack of Iron Ore Resources, ISIJ, Tokyo, (2001), 39.

5) M. Sasaki and Y. Hida: Tetsu-to-Hagané, 68 (1982), 563.

6) A. Muan, E. F. Osborn and S. Munemiya: Phase Equilibria among Oxides in Steelmaking, Gihoudo, Tokyo, (1971), 29.

7) H. Ono-Nakazato, T. Yonezawa and T. Usui: Tetsu-to-Hagané, 89 (2003), 559

8) F. Tsukihashi: Commencement of Creating Porous Meso-mosaic Texture Sinter, ed. by Examination Committee on Agglomeration of Iron Ores Unsuitable for Sintering, ISIJ, Tokyo, (2001), 49.

9) H. Kimura and F. Tsukihashi: CAMP-ISIJ, 16 (2003), 75.

10) R. Baro, H. Moineau and J. J. Heizmann: Advances in X-ray Analysis, Vol. 11, Plenum Press, New York, (1968), 473.

11) K. Meyer, H. Rausch and M. Ottow: Stahl Eisen, 87 (1967), 654.

12) P. Roentgen, H. Winterhager and R. Kammel: Z. Erzbergbau $u$. Metallhüttenwesen, 13 (1960), 363.

13) H. Ono-Nakazato, Y. Tsubone, Y. Takaki and T. Usui: Tetsu-toHagané, 87 (2001), 320.

14) H. Ono-Nakazato, N. Kitamura, Y. Tsubone and T. Usui: Mineral Process. Extractive Metall. Rev., 24 (2003), 269. 